\title{
LA DEVOLUCIÓN DEL PENSAMIENTO A LA VIDA: JULIO C. DA ROSA
}

\author{
POR \\ ELENA ROMITI \\ Instituto de Profesores Artigas
}

Los criollismos, regionalismos y costumbrismos responden a un nominalismo americano que, a partir del uso referencial del lenguaje, comunica la literatura con la vida, en un proceso de significaciones a ubicar en el área de la hermenéutica. $\mathrm{Si}$ actualmente, después de un largo predominio de la literatura de trasfondo campesino en Uruguay, fijamos la atención en la literatura de temática ciudadana, a partir de cuyo auge se aprecia el cambio de horizontes intelectuales gestado desde los años cincuenta, se confirmará el mismo sistema: la hermenéutica de lo diverso es el instrumento para la búsqueda de lo nacional desde el ámbito campero o citadino, indistintamente. La ciudad ya no es el reducto español de la colonia, sino un centro poblado por múltiples tradiciones que, ya asimiladas al contexto uruguayo, han pasado a formar parte de su acervo cultural. Ni el criollismo es sinónimo de lo local, ni la literatura de la ciudad equivale a universalidad. Una vez establecida esta paridad de condiciones, surge la necesidad de observar el movimiento bipolar entre localismo y universalismo, en eterna dependencia, que por debajo del rótulo de criollista o montevideanista, rige la obra del escritor uruguayo. La razón de la lucha por la hegemonía de cada uno de los extremos es una cuestión que algunos autores llegan a explicitar en su obra. Lo cierto es que esta insistencia en el encuentro de la diferencia regional, dentro de la diferencia nacional, involucra una duplicación de esfuerzos por encontrar unaidentidad y la reproducción del cruce cultural originario, una articulación refleja que, a partir del modelo de interrelación de Europa y América, construye el modelo en reducción de la ciudad y el campo.

Julio C. Da Rosa nace en el departamento de Treinta y Tres en 1920, y luego emigra a Montevideo, donde publica su obra literaria desde 1952, integrado a la generación del 45 . Escritor de tránsito, nutre su obra en el lugar de origen, que recupera a partir del recuerdo en ficciones narrativas, en memorias y ensayos. Su obra forma parte de la narrativa criollista nacional, participando de modo subyacente pero ineludible, del movimiento entre lo local y lo universal. Testimonio de universalidad es el gran tema que desarrolla: el hombre y sus trayectos vitales, que son concebidos en íntima relación con la tierra, para 
aferrarse a ella, o para fugarse, según el tiempo. Este último factor implica un núcleo fundamental en la obra del autor, porque la tensión entre tierra y ciudad aparece vinculada a la tensión del pasado con el presente. La mayoría de sus títulos metaforizan ese tiempo de vida que es el hombre: "Cuesta arriba", "De sol a sol", "Camino adentro", "Rumbo sur", "Ratos de padre", involucran la idea del trayecto a recorrer por cada ser humano. El tránsito sustituyente de tiempo por espacio y viceversa, es formulado también a través del diseño de la trilogía novelística: Mundo chico, Rumbo sur y Punto final, que reproduce el viaje desde el mundo campesino de la infancia, hacia la ciudad del interior en la adolescencia, hasta la gran urbe montevideana de la madurez. La última novela no ha sido publicada, a pesar de que su anuncio data de varios años atrás. El hombre se defiende del tiempo volviendo al campo materno, a la infancia dorada, al origen, en una actitud tan universal como que se ajusta perfectamente al viejo paradigma que reza sobre la recuperación del paraíso perdido.

En el cuento "Una casualidad", el proceso que implica un traslado a través del espacio y del tiempo, remite al pasaje desde el estado de indefinición o sin sentido que vive el ser humano hasta que descubre su propia especialidad, equivalente a la noción de la individualidad o diversidad. A través de este logro la vida del hombre llegaría a una verdadera y plena realización. El aserto: "Hombre sin especialidá, es com' ojo sin vista" (18), es el legado que recibe Abedonio Lemos de su padre, cuando queda huérfano en la época de la niñez, siendo un ser sin especialidad, pero poseyendo un rasgo que funciona como indicio de su capacidad para el futuro hallazgo: "Que no sos un cabeza liviana com' otros. Sos seguidor" (19). En la primera de las frases citadas, el padre transmite al hijo el sentido de la vida humana, que se orienta hacia la diversidad. En la culminación del cuento el personaje descubre su especialidad: "para qué había nacido"; fue "por una casualidad. De ésas que se dan una vez en la vida; es decir, una por cada individuo" (18), y todas estas afirmaciones intensifican el carácter único, irrepetible, individual del hallazgo de la respuesta a la interrogante sobre el significado de la vida. Sin embargo, el acto de transmisión entre padre e hijo no está exento del movimiento bipolar enunciado con respecto a la dualidad de lo particular y lo universal, porque el mensaje se entrega al descendiente, permitiendo así la superación del individuo-padre, a través de la continuidad que se realiza en la igualdad de la diferencia: ser hombre es, entonces, oscilar entre el individuo y la especie.

El racconto permite recuperar el largo y esforzado proceso de la búsqueda de la individualidad. las etapas anteriores a este descubrimiento personal son presentadas como desparramo de vida, vida vivida sin sentido ni fin. El gran número de oficios realizados por el personaje con anterioridad al descubrimiento de la especialidad propia delatan su insuficiencia porque los "agarra cualquiera"

1 Julio C. Da Rosa, Hombre-flauta y otros cuentos (Montevideo: Banda Oriental, 1988).

El resto de las citas corresponden a esta edición. 
y "de a uno, no sirven para nada" (18), ellos no definen a un individuo. A través del pasaje por los distintos eslabones que van de "guri de estancia" (22) a peón completo y "hombre de confianza" (24) Abedonio llega a la mayoría de edad, con ella llegan la libertad y el dinero, pero también el desconcierto: "Francamente, no sé qué vi' hacer ni con esta plata ni conmigo" (26). Como en otros relatos, el personaje es huérfano y en el momento de enfrentarse a su propia humanidad necesita del hombre-padre para descubrir su sentido y su destino. La orfandad enfatiza dicha necesidad que tiene el hombre del hombre, quien la satisface se convierte en progenitor más allá del vínculo biológico. En "Una casualidad" parecería ser el patrón de la estancia quien cumplirá este papel, pero en realidad quien lo cumple práctica y cabalmente es Pereira, el cuidador de caballos, que casualmente había sido amigo del padre de Abedonio. Pereira es el máximo exponente del hombre especializado a tal punto que "era uno de estos hombres que se encariñan tanto con una ocupación que se olvidan hasta de casarse" (36). Porque efectivamente casarse significa no ser ni tan diverso ni tan particular como para no alcanzar la superación del individuo a partir del amor. Pereira permite el desarrollo vital de Abedonio al guiarlo hasta que puede llegar a ser él mismo un cuidador. La unicidad del personaje será cuidar de una generalidad de vidas múltiples.

El texto delata a su intertexto y lo contradice, siendo el primer indicio de esta relación el mismo título del cuento, a través del contraste casualidadcausalidad. La casualidad implica un suceso único, irrepetible e impredecible, mientras que la causalidad, por el contrario, implica un suceso reiterable y predecible, ya que a iguales causas pueden presumirse iguales efectos, según norma universal. La relación casualidad-causalidad que el cuento evoca trasunta la relación tensional entre lo particular y lo general, lo local y lo universal, lo individual y lo colectivo.

En el momento del despojo, causado por la muerte de Pereira, el texto dice: "Terminada la discusión, comprendió que estaba al final de aquella casualidad de su vida" (44). No se trataba del final de su especialidad, porque el encuentro con Pereira que había comenzado siendo una casualidad ya no lo era, ya existía una subrepticia permanencia que regiría el destino de Abedonio Lemos. El personaje tenía su especialidad forjada, y ésta sería la determinante de su vida de aquí en más. La casualidad deja de ser tal y pasa a ser causalidad cuando puede alcanzarse la instancia de la recuperación.

Otro caso de especialidad o diversidad en el plano argumental se da en "El hombre-flauta", la diferencia estriba en que aquí la especialidad del personaje central no requiere del proceso de la búsqueda y el aprendizaje, sino que Ansím nace con ella, como un don que la naturaleza le brinda a cuenta de las facultades negadas. La peculiaridad musical le permite alcanzar su plenitud humana a pesar de sus otras carencias. La insignificancia, la marginalidad, el localismo, adquieren su jerarquía en la peculiaridad, permitiendo llegar al todo, a lo general, a la humanidad, al menos en el tiempo de apogeo, que como todo lo humano es fugaz. 
El hecho de que el hombre-flauta y el cuidador de caballos sean personajes humildes, como suele ser constante en la obra de Da Rosa, enfatiza por contraste el rasgo de completitud con que cada vida es registrada; y, en segundo lugar, la idea de que aún en los trayectos vitales más simples se cumplen los movimientos comunes a todos los hombres. El propio autor explica la condición universal de sus criaturas terrícolas:

... debe saberse que aquellos hijos de hombre y mujer, también supieron amar y odiar, gozar y padecer, creer y negar, crear y destruir; esto es, transcurrir en el planeta como el más acabado modelo, hijo de hombre y mujer, en cualesquiera tiempo y lugar del planeta. ${ }^{2}$

Si bien es cierto que cada unidad textual de Da Rosa es una respuesta a la pregunta: ¿Qué es un hombre?, y por ello cada una presenta una trayectoria vital que como un ideograma dibuja hombres a través de sus vidas, también hay textos específicos en que la pregunta ingresa al relato, entonces la intención antropológica se fictiviza, y la función cognitiva es incorporada dentro del corpus literario. Siempre que ello sucede se reitera la imagen arquetípica de un padre en amorosa conversación con el hijo. Ya hemos recordado la frase definitoria que heredara Abedonio Lemos en "Una casualidad". Este cuento mantiene con la primera nouvelle que publica el autor en 1961: Juan de los desamparados, una fuerte relación de complementariedad. Juan Carmona también es huérfano, aunque por otros motivos, pero encuentra su protector en la niñez, y éste tiene una condición excepcional: practica y predica el amor universal. Es así, que la respuesta que entrega Anarolino Sena a Juan sobre el sentido de la vida humana, se orienta a la universalidad del amor que une y no separa. De este modo, la especialidad de "Una casualidad" se complementa con la universalidad de Juan de los desamparados.

Juan Carmona identificaba a Anarolino Sena con:

un gigantesco árbol, especialmente por la sombra que le atribuía a aquel árbol ... Y sobre todo por la condición que también le atribuia, de andarla ofreciendo a cuanto viviente andaba por ahí, medio necesitado de algo (106). ${ }^{3}$

La imagen del árbol posee una proyección simbólica que no sólo repercute sobre la caracterización del padre-protector que ofreció su sombra a Juan, sino que alcanza al sentido de humanidad que venimos registrando: el árbol es el símbolo del hombre, su tronco representa la especie en general, y sus múltiples ramificaciones y hojas, la infinita diversidad de seres que se desprenden del viejo centro originario. No se concibe al hombre sin la especie protectora, ni a

\footnotetext{
2 Julio C. Da Rosa, Mundo chico (Montevideo: Ediciones del Sesquicentenario, 1975), 9.

${ }^{3}$ Julio C. Da Rosa, Novelas cortas (Montevideo: Banda Oriental, 1977). El resto de las citas corresponden a esta edición.
} 
ésta sin la acción específica de cada hombre. El padre habla al hijo "con el cuidado de quien estuviese regando una plantita" (107), porque el ser humano requiere de cuidados. El vínculo, el nexo, la relación son necesarios para seguir siendo humanos.

El diálogo arquetípico es registrado en sus detalles y en sus instancias secuenciales. En primer lugar la formulación de la pregunta iniciática: - "Y sabe lo qu' es ser hombre?”, con su respuesta: “... ser amigo de toditos los otros hombres" (107). En segundo lugar, la interrogante que encamina desde el concepto a la praxis:

-Le gusta estar aquí?

- Me gusta mucho.

-Y por qué le gusta tanto?

-Qué pregunta la suya, don Anarolino! Por qué me va'gustar! Porqu' es lindo, y porqu' está usté qu' es mi compañero (107).

La tercera secuencia dialogal culmina el proceso amoroso con el asentamiento explícito de la relación padre-hijo:

-Escuche bien: a usté no le gustaría que yo fuese su padre?

-Ya pensé: seguro que me gustaría (108).

La muerte de Sena trae como consecuencia inmediata el desalojo del rancho, el encuentro con la intemperie, una nueva orfandad, que ya no es tal porque el personaje posee el sentido de su vida. Sin embargo, la fidelidad al precepto paterno tiene el inconveniente de frenarlo "en su carrera" (109); Juan de los desamparados se inclina decididamente por la superación de loindividual, por la entrega amorosa a la humanidad.

La asunción de toda diferencia a través del amor en el ánimo universalista de Juan se puede descubrir, por ejemplo, en la adopción de los niños que se contradicen por su color:

Pues en compañía de ese rubio como crin de caballo alazán, habría de criarse hasta los seis años aquel negro como crin de caballo zaino, a quienes Carmona había hermanado bajo su apellido .... -Quién l' hubiese créido! - Lo qué? Pues y no ve? Un blanco y un negro besándose (115).

Las vinculaciones de Juan Carmona no se dan sólo con el espectro humano, sino con el mundo natural todo. Cuando en el desarrollo argumental se arriba a los cambios de la modernidad, que irreversiblemente alejan al hombre de la naturaleza, se acerca el final de Juan de los desamparados, porque el progreso trae la ruptura del enlace unificador del hombre con el hombre y su mundo. El proceso es descripto en el sentido de la pérdida: 
Pues en diez años, todo había cambiado .... Se perdieron tiempo adentro, las costumbres más antiguas y consustanciales de la idiosincracia criolla, como el andar a pata de caballo o de buey, el prosear entre cigarro y mate, el vivir al ritmo de la sangre en compañía de algún amigo, algún ocio, algún "dejarse ir" entre cielo y tierra, sin pensar ni en que se existe (135).

Ese "dejarse ir" es la expresión de la entrega, el no pensar involucra un no existir como individuo, en plena unión con el universo.

En el final del relato Juan es despojado de la tierra que había trabajado, y en la que había amado tanto, cobijando a sus desamparados. La separación de la tierra acarrea indefectiblemente la muerte del hombre que fue Juan Carmona, su féretro: "Parecía un cajón de angelito" (142). El personaje representa a un hombre en fluida comunicación con el universo. El mundo moderno ya no alberga este tipo de humanidad, y a ello responde la imagen del "angelito" con que se loidentifica en el último momento. La separación o ruptura de Juan con los hombres y su mundo es simbolizada por el cese de su trayecto vital: "Como una fruta minada por la podredumbre, cayón (142). No existe un corte o separación de mayor intensidad que la muerte.

Desde otro ángulo, pero considerando la ausencia crítica de los enlaces humanos en la sociedad moderna, Carl G. Jung cierra su libro La psicología de la transferencia diciendo:

El fenómeno de la tranferencia es sin duda alguna uno de los síndromes más importantes y significativos del proceso de individuación, e implica algo más que una mera inclinación o aversión personal. Debido a sus contenidos y símbolos colectivos excede en mucho a la persona y toca lo social, recordando las vinculaciones humanas más altas, que, del modo más lamentable, echa de menos nuestro actual orden, o mejor dicho, desorden social ... el hombre masificado no sirve para nada, puesto que sólo es una simple partícula que ha perdido el sentido del ser del hombre, y con ello también el alma. Lo que falta a nuestro mundo es el enlace anímico, y eso no lo puede reemplazar ningún gremio, ninguna comunidad de intereses, ningún partido político, ningún Estado. ${ }^{4}$

Los textos de Julio C. Da Rosa a pesar de ubicarse en el ámbito campesino del origen mítico contienen registros de separación relacionados con la evolución tecnológica de la vida moderna que se centra en la ciudad. En la vida de cada personaje pesa ese rastro de separación. Así en los relatos de los carreros, sustituidos por otros medios de comunicación, como los ferrocarriles, ómnibus o camiones. En los de los músicos, sustituidos por las orquestas profesionales o los discos. En los de los contrabandistas, sustituidos en su calidad de héroes

${ }^{4}$ Carl Gustav Jung, La psicologfa de la transferencia (Bancelona: EditorialPlaneta-Agostini, 1985), 173. 
épicos con imagen de centauros en su mundo de noches peligrosas, por hombres tristes agolpados en asientos de ferrocarriles, etc.

La novela Mundo chico comienza en una clase de la escuela rural número diez en el departamento de Treinta y Tres, y termina con el grito de un personaje que despide a otro, que había sido casi su hermano, cuandoéste ya no lo oye: "así cuando me quede solo tengo un rancho medio cerca, donde echar un real de prosa, y comer tortas fritas los días de lluvia" (486). ${ }^{5}$ El Macho Ramírez le está pidiendo a Perico Lima que envíe desde Montevideo a su madre e hijo para vivir en aquel rincón del mundo. La novela termina, por tanto, con la separación de dos persoanjes que cumplen la función del doble. Ambos habían crecido juntos compartiendo los juegos al aire libre y las clases tediosas, y hasta sus amores. Pero Sebastián Ramírez tuvo un padre y una tierra, mientras Perico crece en medio de carencias, perseguido por los malos tratos de un padrastro "comido por la caña" (13). Juntos acceden a la condición de hombres de respeto cuando se inician como contrabandistas. Sin embargo, en un primer anticipo de separación, Perico reincide en la actividad del contrabando, mientras su amigo: "Con el viejo bastante jodido y él ... enamorado de más" (306), se decide por la esquila. Ramírez se casa con Rufina Fleitas, hija del lugar, mientras Perico emigra a la ciudad, detrás de una maestra, de la cual luego se separa, para casarse nuevamente con otra mujer montevideana.

En el tema del doble subyace la oposición y el conflicto. Estudiando los mitos de gemelos reales o equivalentes en América, Lévi-Strauss comprueba que "tendrán más tarde, aventuras diferentes, que los separarán. ${ }^{6}$ En el caso de Sebastián Ramírez y Perico Lima la separación y el conflicto se ajustan a la separación y conflicto entre campo y ciudad. Para la observación de esta relación presenta un especial interés el intercambio de cartas que se lleva a cabo entre ambos personajes. La primera procede de Montevideo, está firmada por Perico, pero delata la redacción pulida y poética de la maestra, cónyuge del firmante, que sus receptores y antiguos alumnos conocen bien. En la ciudad, el orbe civilizador, la educación triunfa sobre los rasgos primitivos del hombre. La carta, que por su extensión parecía un diario, no es transcripta en su totalidad, sino sólo en los pasajes donde el ataque a la sierra se concreta. La expresión "pozo del universo" (445) introduce una relación de las arideces y pobrezas que caracterizan al lugar, y que a su vez trasmiten una situación de desamor por la tierra.

Y aquí me tiene, hermano, más contento que ratón de despensa -continuaba. Lejos de esas cerrilladas herejes que si nunca me quisieron, menos las quise (446).

B Julio C. Da Rosa, Mundo chico (Montevideo: Ediciones del Sesquicentenario, 1975). El resto de las citas corresponden a esta edición.

6 Claude Lévi-Stauss, Mito y significado (Madrid: Alianza Editorial, 1987), 51. 
El apelativo "hermano" remite al origen similar, sin embargo, la comparación con el ratón sugiere rápidamente la separación. Los ratones, como "todos los roedores exhiben una peculiaridad anátomica que los convierte en gemelos incipientes, pues en cierto modo están divididos en dos mitades, ${ }^{m}$ escribe LéviStrauss relacionando el mito de los labios partidos y los gemelos. A ello se suma la oposición implícita que se tiende entre "ratón de despensa" y "ratón de campo", así como la plasmación de la idea de separación que deriva de las "cerrilladas herejes", en tanto que trazan en el paisaje una línea divisoria, no quedando al margen el calificativo que representa al que disiente. En el final, Perico escribe:

Perdóname, pero lo que cada vez me resisto a creer es que hombres inteligentes como vos no se den cuenta de que no hay más remedio que escurrirle el bulto a esa verruga de la creación -esa puteada del creador-; siempre estoy esperando la noticia de que te vengas para acá (446-447).

A la imagen del "pozo del universo" se le superpone la de "verruga de la creación", siendo ambas contradictorias desde el punto de vista topógrafico, se comprueba que la dualidad está incluida dentro del mismo discurso epistolar. Por otra parte, la presencia de la palabra "universo" en la primera imagen, y "creación" en la segunda, muestra un mismo sistema totalizador envolviendo ambas partes del régimen binario. El "pozo" y la "verruga" como imágenes de valor negativo no dejan de estar incluidas en el todo. La novela en general muestra un fuerte registro cósmico, que absorbe el régimen de los dualismos; se trata de pasajes sin personajes humanos, pero cuyas entidades naturales transfieren la fantasía humanizadora:

Poco a poco aquel sol de setiembre se iba convirtiendo en una verdadera clave; casi un símbolo era, a la segunda semana del entrado el mes; [...] El agua que acumuló la tierra durante el invierno infinito [...] ella también, a modo de una hembra ya cansada de esterilidad, parecía estar aguardando la llegada de aquel sol macho para ordenarse madre paridora. Llegó él con su mansedumbre seductora de semental a pesebre, y a lo largo de pocos días la redujo a sus funciones (241).

La carta de respuesta del Macho Ramírez no se transmite al lector, sino en su espíritu a través de las palabras que el propio personaje adelanta, en diálogo con su esposa, previamente al acto de la escritura:

Te imaginarás que no voy a hablar de malas maestras, ni de hembras, ni de malagradecidos; quiero defenderme, defenderte a vos, defender a nuestros

\footnotetext{
${ }^{7}$ Claude Lévi-Strauss, Mito y significado, 54.
} 
padres ... [...] qué tengo que envidiarle a un peón municipal porque él abra pozos y yo are la tierra; qué diferencia hay entre mamarse en boliche de pueblo y mamarse en el boliche de Martín Medina (450).

La no transcripción de la carta plantea el acceso al contenido a través de la ficción del lenguaje oral. El discurso cumple la función del desahogo por medio de la defensa del pago, y de la réplica a través del cuestionamiento de la diferencia. El momento crucial se da en torno a la imagen del "pozo": asistimos a la inversión de imágenes, Perico la había utilizado metafóricamente, para sustituir a su visión del ámbito oscuro e inferior, mientras que Sebastián la utiliza en su sentido literal: Perico Lima cava pozos reales en Montevideo. La inversión de la imagen refleja una posible inversión de sentido, con respecto a la identificación del referente campo o ciudad.

La escritura involucra una dualidad, que en este caso se relaciona con el valor de la autenticidad y su antivalor. El que escribe como habla y no se corrige, no cumple con la acción escritural en sí y se conserva fiel a sí mismo. Por el contrario, el que realmente escribe, superando la oralidad, se desdobla y se corrige, se separa de sí mismo. En el interjuego del doble uno de los pares posee el valor positivo de la autenticidad y el otro el negativo de la falsedad. El uso de la metáfora "pozo" — dos elementos separados que se superponen sustitutivamente-; la visualización del pasaje epistolar en tanto que palabra escrita, y ratificada por la maestra; el haberse ido de la tierra originaria hacia la ciudad de Montevideo; convierten a Perico Lima en un ser conflictivo y dual en el marco de su propia conciencia. Una nueva formulación del sistema binario campo-ciudad se tiende entre lenguaje oral y lenguaje escrito.

El narrador adopta un discurso ficticio cercano a la oralidad. En sus memorias se manifiesta como comunicador directo, sin dobleces, franco de sentimientos y situaciones:

Pasado este tiempo inmenso - del que tal vez s6lo el puente viejo tenga memoria - he descubierto que no necesitaba más que ser: ser sencilla y humildemente lo que soy: es decir, un hombre que no se niega, para llevarlo por siempre el Olimar en mí. Llevarlo y transmitirlo por herencia a mis hijos. Como una fuerza bio-telúrgica, como un vínculo entrañable, que llegó a mi sangre en la leche de mi madre. ${ }^{8}$

El ser un hombre que no se niega, y que trasmite su localismo - el Olimar es su río-, implica la afirmación del enlace con el origen, el rechazo de toda separación y duplicidad. Sin embargo, la prosecución de este pensamiento presenta dificultades ineludibles en el área de la escritura, como lo advierte el propio autor en las mismas Memorias:

8 Julio C. Da Rosa, Recuerdos de Treinta y Tres (Montevideo: Editorial Asir, 1961), 80. 


\begin{abstract}
Pero es inútil; apenas escrito y lédo lo que antecede, advierto la enorme distancia que separa a quien escribe de quien lee. No puede, no podré nunca abrir a sola punta de pluma el camino, ancho, claro, directo, comodamente transitable que quisiera abrir entre aquel más allá de mi piel y éste más acá de mi pecho [....] Podrá ser la sinceridad el "algo" ése que se me resbala de entre las manos cuando quiero y no pu edo abrir aquel camino? Entonces la sinceridad sería algo así como un calamar, permanentemente dispuesto a cubrir su retirada con el borrón de la propia tinta. Y lo seguro es que cada vez que uno cree tenerla segura - luego de haber zambullido muchas veces en las embravecidas aguas de ese turbulento mar de la conciencia--, lo que realmente tiene son las manos sucias."
\end{abstract}

La escritura es la separación entre un adentro y un afuera, es un destierro, una dualidad. La contrastación ficticia del discurso oral del Macho y el discurso escrito de Perico dramatiza dicho fenómeno. La aparente oralidad de la escritura de Da Rosa testimonia el profundo deseo de superar la distancia con el origen definitivamente perdido en el pasado.

Si la duplicación es el símbolo de la conciencia, a ello arriba el narrador de Mundo Chico, cuando confirma:

Indudablemente, la raíz del asunto estaba en la función de límite que desempeñaba la Cuchilla Grande. El departamento es el departamento. Digase lo que se diga: quien más quien menos necesita encontrar diferencias entre lo que está de este lado y lo que está del otro lado. Sea del océano, de una montaña, de un río o de una piedra. Necesita: ésa es la verdad (19).

La diferencia, en tanto que necesidad humana, resulta ser una manifestación fundamental del discurrir de la conciencia. Y descubrir la correspondencia entre el pensamiento conceptual y el pensamiento mítico y literario conlleva la posibilidad de encontrar una real tradición americana de intento de fusión entre la literatura y la vida, y de convenir con Lévi-strauss en que:

Si llega el día en que el pensamiento haya sido devuelto a la vida, éste será el precio de advertir que la vida es aún más compleja que lo que se suponía y otro tanto ocurrirá con la materia, en tanto jamás se debiera llegar a esta para conducir la vida. Por consiguiente, esto no significa rebajar jamás lo completo hacia lo más simple, sino, por el contrario, en descubrir que cada simplicidad aparente recubre una complejidad insospechada. ${ }^{10}$

9 Julio C. Da Rosa, Recuerdos de Treinta y Tres, 43.

${ }^{10}$ Claude Lévi-Strauss, Mito y significado, 45-46. 


\section{BIBLIOGRAFIA}

Benedetti, Mario. Literatura uruguaya SigloXX. Segunda edición (Montevideo: Alfa, 1969).

Da Rosa, Julio C. Recuerdos de Treinta y Tres (Montevideo: Asir, 1961). Cuentos completos (Montevideo: Banda Oriental, 1966). Civilización y terrofobia (Montevideo: Diálogo, 1968). Ratos de Padre (Montevideo: Banda Oriental, 1968). Buscabichos (Montevideo: Banda Oriental, 1970). Gurises y pájaros (Montevideo: Banda Oriental, 1973). Mundo Chico (Montevideo: Edicones del Sesquicentenario, 1975). Novelas Cortas (Montevideo: Banda Oriental, 1977). Caminos (Montevideo: Banda Oriental, 1978). Antología del cuentocriollo del Uruguay, (conJuan J.DaRosa) (Montevideo: Ediciones de la Plaza, 1979). Rumbo Sur (Montevideo: Banda Oriental, 1980). Hombre-Flauta y otros cuentos (Montevideo: Banda Oriental, 1988).

De Man, Paul. La resistencia a la teoría (Madrid: Visor, 1990).

Jung, Carl Gustav. La psicología de la transferencia (Barcelona: PlanetaAgostini, 1985).

Lévi-Strauss, Claude. Mito y significado (Madrid: Alianza Editorial, 1987). Visca, Arturo Sergio. Aspectos de la narrativa criollista (Montevideo: Biblioteca Nacional, 1972). 
